\title{
Variability in uptake efficiency for pulsed versus constant concentration delivery of inhaled nitric oxide
}

\author{
Andrew R Martin ${ }^{1,4}$, Chris Jackson ${ }^{1,5}$, Ira M Katz ${ }^{2,3^{*}}$ and Georges Caillibotte ${ }^{2}$
}

\begin{abstract}
Background: Nitric oxide (NO) is currently administered using devices that maintain constant inspired NO concentrations. Alternatively, devices that deliver a pulse of NO during the early phase of inspiration may have use in optimizing NO dosing efficiency and in extending application of NO to long-term use by ambulatory, spontaneously breathing patients. The extent to which the amount of NO delivered for a given pulse sequence determines alveolar concentrations and uptake, and the extent to which this relationship varies with breathing pattern, physiological, and pathophysiological parameters, warrants investigation.
\end{abstract}

Methods: A mathematical model was used to analyze inhaled nitric oxide (NO) transport through the conducting airways, and to predict uptake from the alveolar region of the lung. Pulsed delivery was compared with delivery of a constant concentration of $\mathrm{NO}$ in the inhaled gas.

Results: Pulsed delivery was predicted to offer significant improvement in uptake efficiency compared with constant concentration delivery. Uptake from the alveolar region depended on pulse timing, tidal volume, respiratory rate, lung and dead space volume, and the diffusing capacity of the lung for $N O\left(D_{\llcorner} N O\right)$. It was predicted that variation in uptake efficiency with breathing pattern can be limited using a pulse time of less than $100 \mathrm{~ms}$, with a delay of less than $50 \mathrm{~ms}$ between the onset of inhalation and pulse delivery. Nonlinear variation in uptake efficiency with $D_{\llcorner} N O$ was predicted, with uptake efficiency falling off sharply as $D_{\llcorner} N O$ decreased below $50-60 \mathrm{ml} / \mathrm{min} / \mathrm{mm} \mathrm{Hg}$. Gas mixing in the conducting airways played an important role in determining uptake, such that consideration of bulk convection alone would lead to errors in assessing efficiency of pulsed delivery systems.

Conclusions: Pulsed NO delivery improves uptake efficiency compared with constant concentration delivery. Optimization of pulse timing is critical in limiting intra- and inter-subject variability in dosing.

Keywords: Lung model, Trumpet model, Medical gas, Nitric oxide, Gas transport, Conducting airways, Mixing, Dispersion, Bolus, Pulse

\section{Background}

Inhaled nitric oxide (NO) has been shown to act as a selective pulmonary vasodilator $[1,2]$. Since this discovery more than 20 years ago, use of $\mathrm{NO}$ has become widespread for treating persistent pulmonary hypertension of the newborn (PPHN) [3], improving oxygenation in adult patients with acute lung injury or the acute respiratory distress syndrome [4], and in alleviating pulmonary hypertension in

\footnotetext{
*Correspondence: ira.katz@airliquide.com

${ }^{2}$ Medical Gases Group, Air Liquide Santé International, 1 chemin de la Porte des Loges, Les Loges-en-Josas 78354, France

${ }^{3}$ Department of Mechanical Engineering, Lafayette College, Easton, PA, USA

Full list of author information is available at the end of the article
}

adults and children following cardiac surgery [5,6]. These settings generally require NO to be delivered to mechanically ventilated patients. To do so, delivery devices have been developed which administer NO from a source cylinder containing 100-1000 ppm NO (800 ppm NO in North America) in balance nitrogen, to the inspiratory limb of the patient breathing circuit. The flow rate of NO injection is adjusted in proportion to the flow of air/oxygen in the circuit so as to produce a constant $\mathrm{NO}$ concentration in the inspired gas $[7,8]$. Accordingly, dosing recommendations for inhaled NO have been established based on the NO concentration in inspired gas $[4,9]$. 
For some time, researchers have speculated that the dose-response relationship for inhaled NO might be better described in terms of alveolar concentration or uptake from the lungs, rather than inhaled concentration $[10,11]$. Such considerations have often been made in the context of pulsed NO delivery systems, which deliver a predetermined volume of $\mathrm{NO}$ in the early portion of inhalation, with the goal of maximizing delivery to the peripheral, gas exchange lung regions, while avoiding delivery of NO to the anatomical dead space near the end of inhalation [11-15]. Pulsed systems may have use in optimizing dosing and minimizing total $\mathrm{NO}$ usage for intubated, ventilated patients, but also in extending application of NO to long-term use by ambulatory, spontaneously breathing patients. However, these systems are inherently poorly described using the established dose metric of inhaled NO concentration, as the concentration is intentionally varied over each inhalation. Instead, they are potentially well adapted for dosing in terms of the absolute amount (volume, mass, moles) of NO delivered per breath or over a given time period. The extent to which the amount of NO delivered for a given pulse sequence determines alveolar concentrations and uptake, and the extent to which this relationship varies with breathing pattern, and with physiological and pathophysiological parameters, is presently unclear, and thus warrants study.

This article describes a mathematical model developed to couple gas mixing and transport through the conducting airways with uptake from the alveolar lung region. Continuous or pulsed NO delivered to the extrathoracic airway was transported through serial airway generations by a combination of bulk convection and axial dispersion. Uptake from the alveolar region was determined as a function of alveolar volume and NO concentration, as well as the diffusing capacity of the lung for NO. The model was used to evaluate equivalency, in terms of alveolar concentration and uptake, between constant concentration and pulsed $\mathrm{NO}$ dosing, and to establish framework recommendations on pulse volume, duration, and delay time (between onset of inhalation and pulse delivery) for optimal uptake efficiency. In addition, the significance of axial dispersion on $\mathrm{NO}$ transport, and ultimately uptake, was evaluated, as was the sensitivity of uptake efficiency to the lung's diffusing capacity for NO.

\section{Methods}

\section{Modeling approach}

A single compartment, single path lung model was employed. The lung was divided into a gas-conducting region and an alveolar region. It was assumed that zero uptake of NO occurred across the conducting airways, whereas uptake from the alveolar region into the capillaries was modeled with a single transfer factor specifying volume uptake per unit time per unit partial pressure (i.e., $\mathrm{D}_{\mathrm{L}} \mathrm{NO}$ - the diffusing capacity of the lung for NO). Inputs to the model included the $\mathrm{D}_{\mathrm{L}} \mathrm{NO}$, along with the functional residual capacity (FRC) of the lung, the dimensions of the conducting airways, the breathing pattern (inhaled and exhaled volumetric flow rates vs. time), and the variation in inhaled NO concentration specified over time. Outputs of the model included the time-varying concentrations of NO in each generation of the conducting airways and in the alveolar region, the rate at which $\mathrm{NO}$ was taken up into the capillaries, and the NO concentration in the exhaled gas.

\section{Conducting airways}

The tracheobronchial airways making up the gasconducting region of the lung can be described as a symmetric, bifurcating network of rigid, cylindrical tubes starting at the trachea and extending to the terminal bronchioles. In the present work, baseline dimensions of the conducting airways were specified according to the adult model provided by Finlay et al. [16], based on airway data from Phillips et al. [17]. These are provided in Table 1, and correspond to a FRC of the lung of $3000 \mathrm{ml}$. Airway lengths and diameters were then scaled with FRC according to

$$
\ell=\ell_{0}\left(\frac{F R C}{3000 m l}\right)^{1 / 3}
$$

Table 1 Conducting airway dimensions from Finlay et al.

[16]

\begin{tabular}{lrrr}
\hline GEN\# & Diameter $(\mathbf{c m})$ & Length $(\mathbf{c m})$ & Volume $^{*}(\mathbf{m l})$ \\
\hline 0 & 1.80 & 12.46 & 32.05 \\
1 & 1.41 & 3.61 & 11.35 \\
2 & 1.12 & 2.86 & 11.17 \\
3 & 0.89 & 2.28 & 11.22 \\
4 & 0.71 & 1.78 & 11.13 \\
5 & 0.57 & 1.13 & 9.03 \\
6 & 0.45 & 0.90 & 9.29 \\
7 & 0.36 & 0.83 & 11.00 \\
8 & 0.29 & 0.75 & 12.22 \\
9 & 0.22 & 0.65 & 12.46 \\
10 & 0.16 & 0.56 & 11.79 \\
11 & 0.12 & 0.45 & 10.67 \\
12 & 0.09 & 0.36 & 9.74 \\
13 & 0.07 & 0.28 & 9.53 \\
14 & 0.06 & 0.22 & 10.49 \\
\hline
\end{tabular}

*Total volume of $2^{n}$ airways in generation $n$. 
where $\ell$ represents the scaled length or diameter, and $\ell_{\mathrm{o}}$ represents the corresponding length or diameter at FRC of $3000 \mathrm{ml}$.

Proximal to the trachea, an extrathoracic airway was defined by a characteristic diameter and length of $0.75 \mathrm{~cm}$ and $30 \mathrm{~cm}$, respectively, to represent an adult endotracheal tube.

Dispersion of inhaled NO through the extrathoracic and conducting airways was analyzed following an approach analogous to the Eulerian dynamical framework outlined by Finlay [18] for modeling aerosol transport through the respiratory tract. In brief, the convectiondiffusion equation was solved in one dimension over a single path, with the coordinate $x$ representing the depth into the lung along that path. The conducting airway dimensions described above were used to define the total cross-sectional area of airways in the lung as a function of $x$. It was assumed that the flux of NO through airway walls was zero, and that conducting airway crosssections remained constant over time. The 1D transport equation could then be written in differential form as

$$
\frac{\partial}{\partial t}(A \bar{c})+\frac{\partial}{\partial x}(A \bar{c} \bar{u})=\frac{\partial}{\partial x}\left(A D_{m} \frac{\partial \bar{c}}{\partial x}\right)
$$

where $A$ is the total cross-sectional area of airways in the lung at a given depth $x, \bar{c}$ is the NO concentration averaged over the area $A, \bar{u}$ is the average flow velocity in the $x$-direction over the area $A$, and $D_{m}$ is the molecular diffusivity of NO in air.

Equation (2) assumes both the velocity and the NO concentration are uniform across the area $A$. In general, these variables are not uniform, and their variation across the entire airway cross section at a given lung depth is complex. To preserve the simplicity of the 1D model, a common approach is to replace $D_{m}$ with an effective diffusion coefficient $D_{\text {eff, }}$ the latter acting as a catch-all term encompassing both molecular diffusion and various convective-diffusive dispersion phenomena arising from non-uniform velocity and concentration profiles. The effective diffusion coefficient can thus be written as the summation

$$
D_{e f f}=D_{m}+D_{c-d}
$$

where $D_{c-d}$ represents the contribution of convectivediffusive dispersion to the total effective diffusive flux.

Ben-Jebria [19] presented compelling arguments that flow patterns through the conducting airways are sufficiently complex that gas mixing cannot be described using the laminar dispersion model described by Taylor [20], but should instead be estimated based on experiments performed by Scherer et al. [21] on gas dispersion in a physical model of the first five branches of the conducting airways. In the latter approach, the dispersion coefficient is

$$
D_{c-d}=\alpha \bar{u} d
$$

where $\alpha$ is an empirical constant equal to 1.08 during inhalation and 0.37 during exhalation, and $d$ is the diameter of the airway.

Using equation (4), $D_{c-d}$ may be calculated and compared to $D_{m}$ for each generation of the conducting airways. This was done for airway velocities $\bar{u}$ corresponding to a $300 \mathrm{ml} / \mathrm{s}$ inspiratory flow rate and $500 \mathrm{ml} / \mathrm{s}$ expiratory flow rate using airway diameters specified in the Finlay et al. [16] airway model described above, and using a molecular diffusivity of $\mathrm{NO}$ in air of $0.23 \mathrm{~cm}^{2} / \mathrm{s}$. The comparison is presented in Figure 1, where it can be seen that $D_{c-d}$ is much greater than $D_{m}$ during both inhalation and exhalation through most of the conducting airways, but that molecular diffusivity becomes non-negligible in the small airways approaching the transition to the alveolar region.

With $D_{m}$ replaced by $D_{\text {eff }}$, equation (2) can be reorganized as

$$
A \frac{\partial \bar{c}}{\partial t}=\frac{\partial}{\partial x}\left(A D_{e f f} \frac{\partial \bar{c}}{\partial x}\right)-\frac{\partial}{\partial x}(A \bar{c} \bar{u})
$$

For each case studied, the time variation of $\mathrm{NO}$ concentration was specified at the entrance to the extrathoracic airway, the concentration gradients at the entrance and at the boundary between conducting airways and the alveolar region were set to zero, and the initial

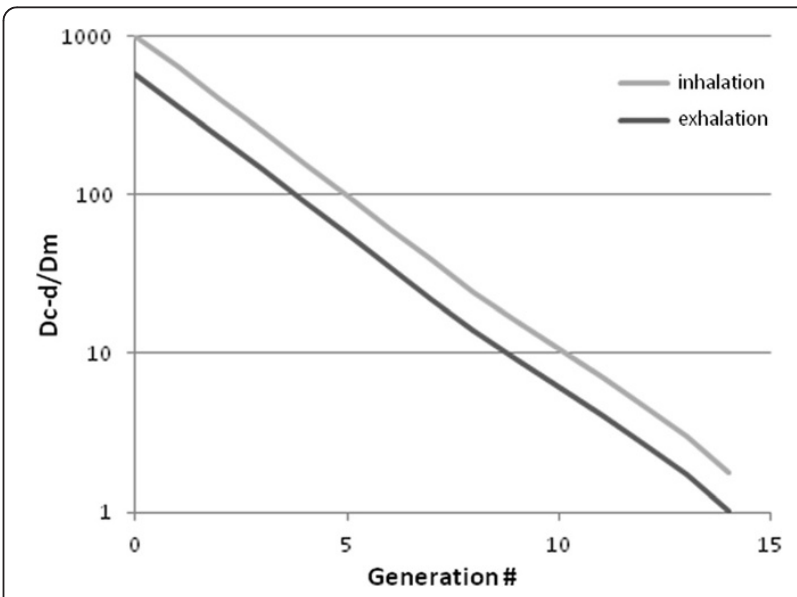

Figure 1 Ratio between the two components of the effective diffusion coefficient during inhalation and exhalation over the conducting airways. 
NO concentration was set to zero throughout the geometry. That is

$$
\begin{gathered}
\bar{c}(x=0, t)=f(t) \\
\left.\frac{\partial \bar{c}}{\partial x}\right|_{x=0} ^{t}=\left.\frac{\partial \bar{c}}{\partial x}\right|_{x=L} ^{t}=0 \\
\bar{c}(x, t=0)=0
\end{gathered}
$$

where $f(t)$ specifies the inhaled NO concentration over time, and $x=L$ denotes the boundary between conducting airways and alveolar region.

\section{Alveolar region}

The alveolar region was modeled as a single, well-mixed compartment that expanded and contracted during the breathing cycle consistent with the inhaled and exhaled tidal volume. The mass conservation of NO in the alveolar region during inhalation can be written as

$$
\frac{\mathrm{d}\left(c_{a l v} V_{a l v}\right)}{\mathrm{d} t}=\bar{c}_{14} Q-c_{a l v} D_{L} N O
$$

and during exhalation as

$$
\frac{\mathrm{d}\left(c_{a l v} V_{a l v}\right)}{\mathrm{d} t}=c_{a l v} Q-c_{a l v} D_{L} N O
$$

where

$$
\frac{\mathrm{d} V_{a l v}}{\mathrm{~d} t}=Q(t)
$$

and where $Q$ is the instantaneous volumetric flow rate of gas into or out of the lungs, $V_{a l v}$ is the volume of the alveolar region, $c_{a l v}$ and $\bar{c}_{14}$ represent the NO concentrations in the alveolar region and in the terminal bronchioles (generation 14), respectively, and $D_{L} N O$ is the diffusing capacity of the lung for $\mathrm{NO}$. $\mathrm{D}_{\mathrm{L}} \mathrm{NO}$ is normally specified as the volume uptake of $\mathrm{NO}$ per unit time per unit partial pressure, but as written in equations (7) and (8) $\mathrm{D}_{\mathrm{L}} \mathrm{NO}$ must be expressed in units of the quantity of $\mathrm{NO}$ conserved (i.e., mass, moles, or volume at STP) per unit time per unit concentration.

After expanding the left hand sides of equations (7) and (8) using the product rule, and rearranging terms, the rate of change of alveolar concentration of $\mathrm{NO}$ was determined during inhalation as

$$
\frac{\mathrm{d} c_{a l v}}{\mathrm{~d} t}=\frac{\left(\bar{c}_{14}-c_{a l v}\right) Q-c_{a l v} D_{L} N O}{V_{a l v}}
$$

and during exhalation as

$$
\frac{\mathrm{d} c_{a l v}}{\mathrm{~d} t}=\frac{-c_{a l v} D_{L} N O}{V_{a l v}}
$$

\section{Numerical procedure}

Equation (5) was discretized and solved through the extrathoracic and conducting airways over finite divisions of length using an upwind approximation for the convective term and a central difference approximation for the diffusive term. The discretized transport equation during inhalation was

$$
\begin{gathered}
C_{i}^{t}=C_{i}^{t-\Delta t}+\left(C_{i+1}^{t-\Delta t}-C_{i}^{t-\Delta t}\right) \frac{\bar{u}_{i}^{t}}{l_{i}} \Delta t \\
+\frac{1}{2}\left[\left(A_{i-1}+A_{i}\right)\left(\operatorname{Deff}_{i-1}^{t}+\operatorname{Deff}_{i}^{t}\right)\left(\frac{C_{i-1}^{t-\Delta t}-C_{i}^{t-\Delta t}}{l_{i-1}+l_{i}}\right)\right. \\
\left.-\left(A_{i}+A_{i+1}\right)\left(\operatorname{Deff}_{i}^{t}+\operatorname{Deff}_{i+1}^{t}\right)\left(\frac{C_{i+}^{t-\Delta t}}{l_{i}+l_{i+1}}\right)\right] \frac{\Delta t}{l_{i} A_{i}}
\end{gathered}
$$

and during exhalation was

$$
\begin{gathered}
C_{i}^{t}=C_{i}^{t-\Delta t}+\left(C_{i-1}^{t-\Delta t}-C_{i}^{t-\Delta t}\right) \frac{\bar{u}_{i}^{t}}{l_{i}} \Delta t \\
+\frac{1}{2}\left[\left(A_{i-1}+A_{i}\right)\left(\operatorname{Deff}_{i-1}^{t}+\operatorname{Deff}_{i}^{t}\right)\left(\frac{C_{i-1}^{t-\Delta t}-C_{i}^{t-\Delta t}}{l_{i-1}+l_{i}}\right)\right. \\
\left.-\left(A_{i}+A_{i+1}\right)\left(\operatorname{Deff}_{i}^{t}+\operatorname{Deff}_{i+1}^{t}\right)\left(\frac{C_{l_{i}}^{t-\Delta t}-C_{i+1}^{t-\Delta t}}{l_{i}+l_{i+1}}\right)\right] \frac{\Delta t}{l_{i} A_{i}}
\end{gathered}
$$

where $C_{i}^{t}$ is the NO concentration in the $\mathrm{i}^{\text {th }}$ division at time $\mathrm{t}$, and $l_{i}$ is the length of the $\mathrm{i}^{\text {th }}$ division. The parameters $\bar{u}_{i}^{t}$ and $D_{\text {eff, } i}^{t}$ were known, and prescribed at the start of the procedure based on the specified breathing pattern and airway dimensions.

Alveolar concentrations were calculated directly using the finite difference versions of equations (10) and (11) during inhalation and exhalation, respectively.

Concentrations throughout the respiratory tract were calculated explicitly over time via the Euler method. To assess time step and spatial grid size dependence, initial calculations were performed with 1000, 2500, 5000, or 10000 equal time steps per breath, and for 1,2 , 3 , or 5 equal length divisions per generation. For constant inhaled NO concentrations, increasing the number of time steps per breath or divisions per generation had negligible effect on NO uptake and uptake efficiency, save that in the case of 5 divisions per generation 5000 time steps per breath were required for convergence. For calculations performed for pulsed NO delivery, increasing the number of divisions per generation from 1 to 3 reduced NO uptake and uptake efficiency slightly, while further increase above 3 divisions had negligible effect. Effects of time step size were negligible, save that again 5000 time steps per breath were required for convergence in the case of 5 divisions per generation. For all combinations of time step and divisions, convergence or divergence of the solution was well predicted by 
applying the practical criterion given by Darquenne and Paiva [22] at the terminal conducting airway (generation 14 in the present model). Results presented below were obtained using 5 divisions per generation and 5000 time steps per breath.

\section{Cases studied}

The model presented above was first verified through comparison with a model previously proposed by Heinonen et al. [11], which compared well with in vivo exhaled NO concentrations measured by the same authors during continuous and pulsed delivery of NO to intubated, mechanically ventilated pigs. For the purpose of comparison, all parameters were set equal to those reported by Heinonen et al. [11]. The idealized flow pattern described in Figure 2 was adopted, with tidal volume of $400 \mathrm{ml}$, respiratory rate of $20 \mathrm{~min}^{-1}$, inspiratory time fraction equal to $1 / 3$ of the breath, and the expiratory time constant equal to $0.37 \mathrm{~s}$. In addition, the $\mathrm{D}_{\mathrm{L}} \mathrm{NO}$ was set to $48 \mathrm{ml} / \mathrm{min} / \mathrm{mm} \mathrm{Hg}, \mathrm{FRC}$ to $700 \mathrm{ml}$, and airway dimensions were scaled to yield an anatomical dead volume of $150 \mathrm{ml}$. Following Heinonen et al. [11], the NO concentration in inhaled gas was either set to a constant $5 \mathrm{ppm}$ throughout inhalation, or, for the case of pulsed delivery of $100 \mathrm{nmol} \mathrm{NO} / \mathrm{min}$, a $110 \mu \mathrm{l}$ pulse containing 1000 ppm NO in balance nitrogen was injected during only the first third of each inhalation at a flow rate of $0.33 \mathrm{ml} / \mathrm{s}$. In the latter case, the $\mathrm{NO} / \mathrm{N}_{2}$ stream was assumed to be well mixed with the inhaled air stream at the entrance to the extrathoracic region. Alveolar $\mathrm{NO}$ concentrations $\left(\mathrm{F}_{\mathrm{A}} \mathrm{NO}\right)$, $\mathrm{NO}$ uptake efficiency (defined as the mass of $\mathrm{NO}$ absorbed from the alveolar region divided by the mass of $\mathrm{NO}$ inhaled), and exhaled $\mathrm{NO}$ concentrations $\left(\mathrm{F}_{\mathrm{E}} \mathrm{NO}\right)$ were compared between the present model and that proposed by Heinonen et al. [11]. In addition, model predictions were compared with exhaled peak and end-tidal NO concentrations measured in pigs by Heinonen et al. [11] for the cases of constant 5 ppm NO delivery, and pulsed delivery of $100 \mathrm{nmol} \mathrm{NO} / \mathrm{min}$.

Subsequent calculations were performed using the present model to simulate constant and pulsed delivery of NO to adult humans. A base parameter set was defined with FRC of $3000 \mathrm{ml}, \mathrm{D}_{\mathrm{L}} \mathrm{NO}$ of $150 \mathrm{ml} / \mathrm{min} / \mathrm{mm} \mathrm{Hg}$, tidal volume of $500 \mathrm{ml}$, breath frequency of $12 \mathrm{~min}^{-1}$, inspiratory time fraction of $1 / 3$, and expiratory time constant of $0.6 \mathrm{~s}$. Individual parameters were varied to explore their effects on NO uptake and uptake efficiency. The breathing pattern took the form shown in Figure 2, with constant inhalation flow and an exponentially-decaying exhalation flow. The coefficient $A$ defining the peak expiratory flow was calculated for a given inhaled tidal volume, expiratory time constant, and expiratory time so as to set the exhaled tidal volume equal to the inhaled tidal volume.

Proportional delivery was modeled using a constant $20 \mathrm{ppm}$ inhaled concentration of NO. Three different pulse durations, $t_{\text {pulse, }}$, were studied: 100, 200, and 400 ms. Pulses were modeled as square waves as depicted in Figure 2. Each pulse delivered $8 \mu \mathrm{g} \mathrm{NO} /$ breath (equivalent to $267 \mathrm{nmol}$ $\mathrm{NO} /$ breath). This dose was chosen based on initial calculations performed using the model so as to yield equivalent alveolar NO concentration and uptake for the base parameter set as the constant 20 ppm delivery case. For $t_{\text {pulse }}$ of 100, 200, and $400 \mathrm{~ms}, 800 \mathrm{ppm} \mathrm{NO}$ in balance $\mathrm{N}_{2}$ was

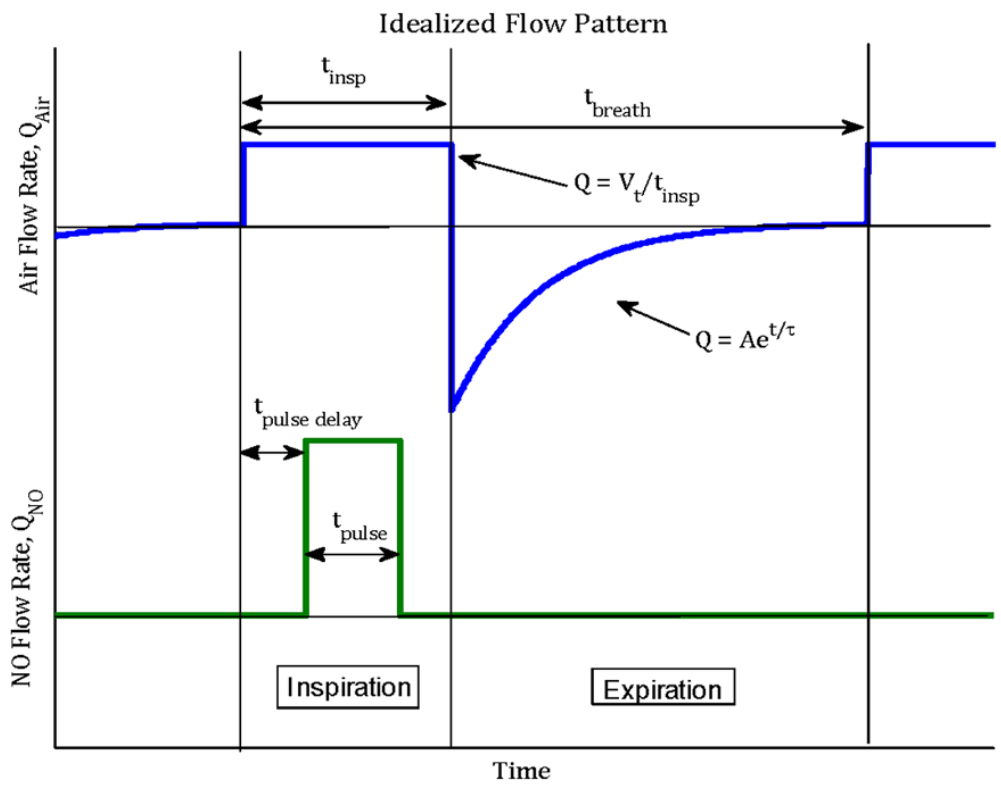

Figure 2 Idealized breathing pattern (top) and pulse form (bottom) used as inputs to the model. 
introduced at 75, 37.5 and $18.75 \mathrm{~mL} / \mathrm{s}$, respectively. Again, the $\mathrm{NO} / \mathrm{N}_{2}$ stream was assumed to be well mixed with the inhaled air stream at the entrance to the extrathoracic region. The effect of delay between the start of inspiration and pulse delivery was studied by setting a pulse delay, $t_{\text {pulse delay, }}$ of $0,50,100,200 \mathrm{~ms}$.

\section{Results}

\section{Model verification}

Table 2 lists peak and end tidal values of the alveolar $\mathrm{NO}$ concentration, $\mathrm{F}_{\mathrm{A}} \mathrm{NO}$, and exhaled $\mathrm{NO}$ concentration, $\mathrm{F}_{\mathrm{E}} \mathrm{NO}$, predicted using the present model and the model presented by Heinonen et al. [11], as well as average peak and end tidal values of $\mathrm{F}_{\mathrm{E}} \mathrm{NO}$ from experiments in intubated, mechanically ventilated pigs presented by the same authors. NO uptake efficiency as determined by the two models is also presented. In general, very close agreement was seen between the two models.

\section{Constant concentration versus pulsed dosing}

Figure 3 displays variation of $\mathrm{NO}$ concentration over time and location from delivery through the segmental bronchi (generation 3), and in the alveolar region, for constant $20 \mathrm{ppm}$ delivery, and for delivery of a $100 \mathrm{~ms}$ pulse containing $800 \mathrm{ppm} \mathrm{NO}$ at $75 \mathrm{ml} / \mathrm{s}$ into the inhalation flow, with zero pulse delay. Concentrations for both delivery modes are presented for the base parameter set. Figure 4 shows alveolar concentrations at a more appropriate concentration scale, for both the constant $20 \mathrm{ppm}$ delivery, and for the three pulse delivery cases, again for the base parameter set. The pulse volumes were set so as to achieve very similar alveolar concentrations as for the constant 20 ppm case.

Variation in NO uptake and NO uptake efficiency with breathing and physiological parameters is shown in Figures 5 and 6, respectively. All plots in Figure 5 include a point of intersection between the pulsed and constant delivery modes, consistent with the choice of pulse volume to yield equivalent alveolar NO concentration as constant $20 \mathrm{ppm}$ delivery for the base parameter set. No points of intersection between modes exist in Figure 6, where in all cases the NO uptake efficiency is significantly lower for constant than for pulsed delivery.

\section{Effects of pulse delay}

Uptake efficiency is provided is Table 3 for varying time delays between the start of inhalation and delivery of the NO pulse. Data is provided for the base parameter set, with tidal volume $\left(\mathrm{V}_{\mathrm{t}}\right)$ of $500 \mathrm{ml}$ and breathing frequency (f) of $12 \mathrm{~min}^{-1}$, as well as for three other combinations with $\mathrm{V}_{\mathrm{t}}=250 \mathrm{ml}$ and $/$ or $\mathrm{f}=25 \mathrm{~min}^{-1}$. All other parameters were held constant at values defined for the base parameter set. While uptake efficiency remained above 0.9 for all combinations of pulse time and delay for $\mathrm{V}_{\mathrm{t}}=500 \mathrm{ml}$ and $\mathrm{f}=12 \mathrm{~min}^{-1}$, efficiency decreased dramatically with pulse time and delay for the case of rapid, shallow breathing with $\mathrm{V}_{\mathrm{t}}=250 \mathrm{ml}$ and $\mathrm{f}=25 \mathrm{~min}^{-1}$.

\section{Uptake efficiency versus $D_{\mathrm{L}} \mathrm{NO}$}

Figure 7 plots variation in uptake efficiency with $\mathrm{D}_{\mathrm{L}} \mathrm{NO}$ for constant delivery of $20 \mathrm{ppm} \mathrm{NO}$ and for the $100 \mathrm{~ms}$ pulsed delivery, for two breathing patterns. In all cases studied, uptake efficiency was relatively constant for $\mathrm{D}_{\mathrm{L}} \mathrm{NO}$ larger than $\sim 80 \mathrm{ml} / \mathrm{min} / \mathrm{mm} \mathrm{Hg}$, increasing by less than 0.1 as $\mathrm{D}_{\mathrm{L}} \mathrm{NO}$ increased up to $200 \mathrm{ml} / \mathrm{min} / \mathrm{mm} \mathrm{Hg}$. However, uptake efficiency became more sensitive to $\mathrm{D}_{\mathrm{L}} \mathrm{NO}$ at values less than $\sim 80 \mathrm{ml} / \mathrm{min} / \mathrm{mm} \mathrm{Hg}$, and began to drop off sharply as $\mathrm{D}_{\mathrm{L}} \mathrm{NO}$ fell below $\sim 50-60 \mathrm{ml} / \mathrm{min} / \mathrm{mm} \mathrm{Hg}$.

\section{Discussion}

Uptake of NO from the alveolar region depended on pulse timing, tidal volume, respiratory rate, lung and

Table 2 Comparison of nitric oxide concentrations and uptake efficiencies in intubated, mechanically ventilated pigs

\begin{tabular}{|c|c|c|c|c|c|}
\hline Delivery mode & $\begin{array}{c}\mathrm{F}_{\mathrm{A}} \mathrm{NO}, \text { peak } \\
{[\mathrm{ppb}]}\end{array}$ & $\begin{array}{c}\mathrm{F}_{\mathrm{A}} \mathrm{NO} \text {, end tidal } \\
{[\mathrm{ppb}]}\end{array}$ & $\begin{array}{c}\mathrm{F}_{\mathrm{E}} \mathrm{NO}, \text { peak } \\
{[\mathrm{ppb}]}\end{array}$ & $\begin{array}{c}\mathrm{F}_{\mathrm{E}} \mathrm{NO} \text {, end tidal } \\
{[\mathrm{ppb}]}\end{array}$ & $\begin{array}{c}\text { Uptake } \\
\text { Efficiency }\end{array}$ \\
\hline \multicolumn{6}{|l|}{ Present model: } \\
\hline 5 ppm constant & 1066 & 216 & 5000 & 840 & 0.49 \\
\hline $100 \mathrm{nmol} / \mathrm{min}$ pulsed & 100 & 17 & 79 & 68 & 0.80 \\
\hline \multicolumn{6}{|c|}{ Heinonen et al. [11] model: } \\
\hline 5 ppm constant & 1250 & 250 & 5000 & 820 & 0.51 \\
\hline $100 \mathrm{nmol} / \mathrm{min}$ pulsed & 125 & 25 & 90 & 67 & 0.83 \\
\hline \multicolumn{6}{|c|}{ Heinonen et al. [11] data*: } \\
\hline 5 ppm constant & - & - & 4700 & 890 & - \\
\hline $100 \mathrm{nmol} / \mathrm{min}$ pulsed & - & - & 90 & 60 & - \\
\hline
\end{tabular}

${ }^{*}$ As reported in Heinonen et al. [11] based on experimental regression values.

$F_{A} N O=$ Alveolar fraction of $\mathrm{NO}$.

$F_{E} N O=$ Exhaled fraction of NO.

Uptake Efficiency $=$ (NO uptake)/(NO inhaled). 

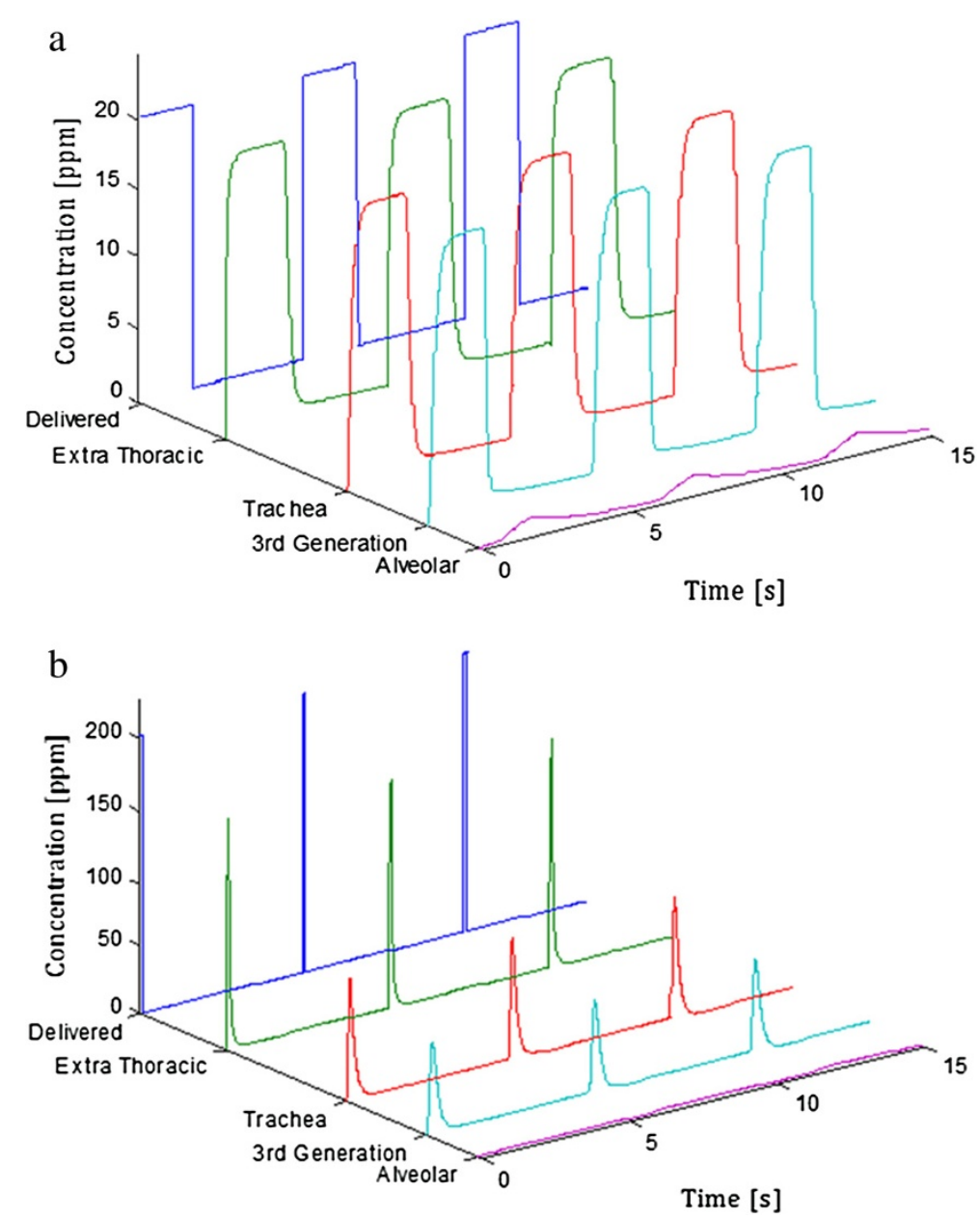

Figure 3 Regional variation of NO concentration over time. Shown for (a) delivery of a constant 20 ppm concentration during inhalation and (b) delivery of a $100 \mathrm{~ms}$ pulse containing $800 \mathrm{ppm} \mathrm{NO}$ at $75 \mathrm{ml} / \mathrm{s}$ into the inhalation flow, sequenced with the start of each inhalation with zero pulse delay. Note the difference in concentration scales between the two plots. Alveolar concentrations are displayed on a more appropriate scale in Figure 4.

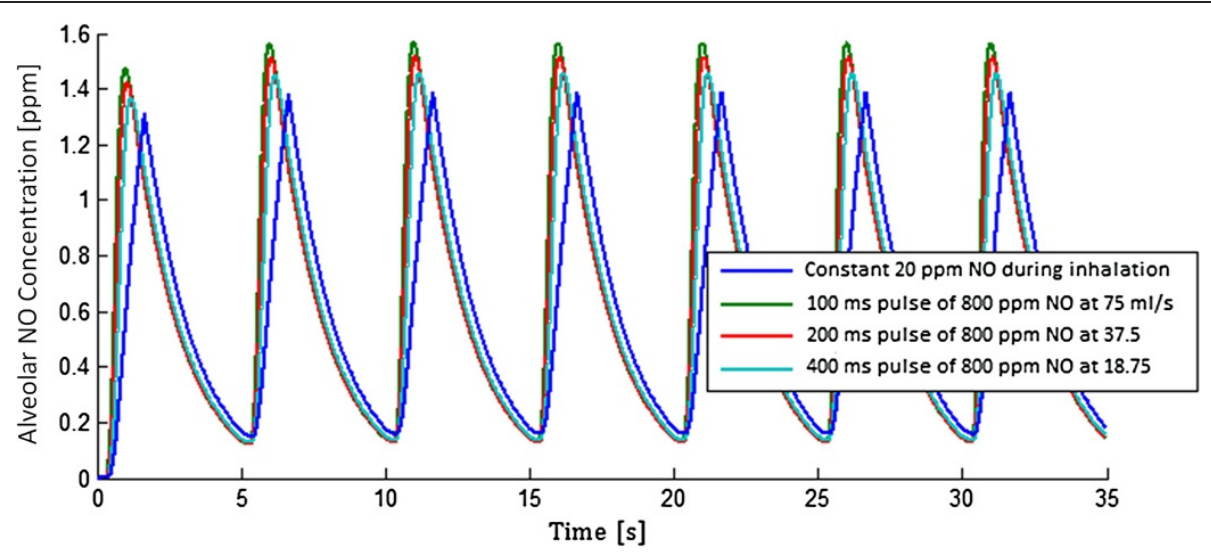

Figure 4 Alveolar NO concentration $\left(\mathrm{F}_{\mathrm{A}} \mathrm{NO}\right)$ versus time for the first 7 breaths after starting constant or pulsed NO delivery. Pulsed dosing was sequenced with the start of each inhalation with zero pulse delay. 

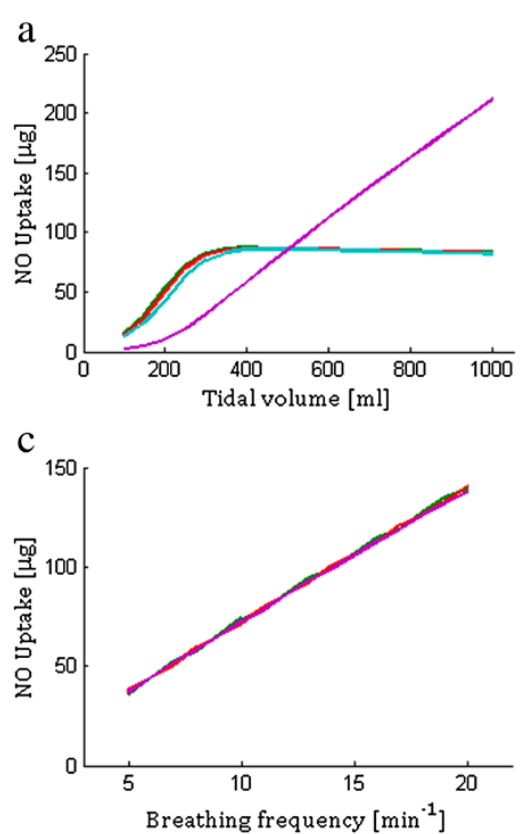

e

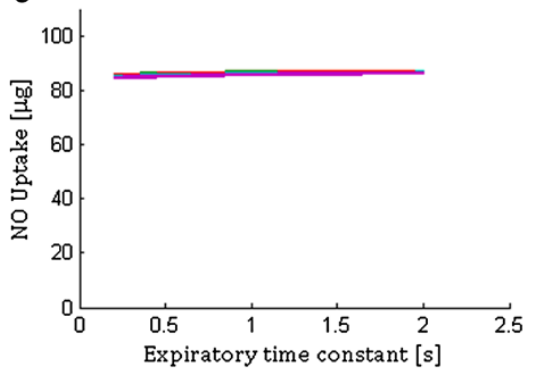

b

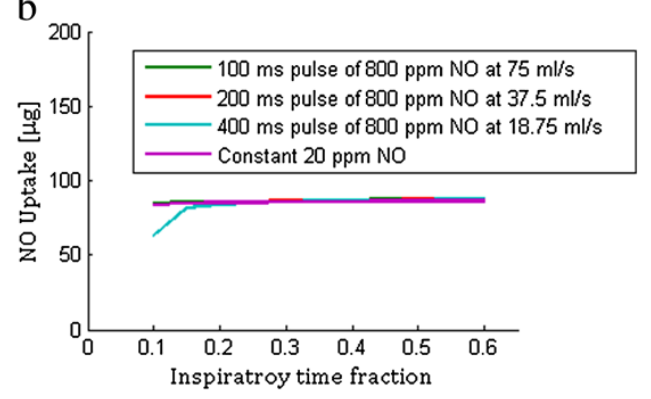

d

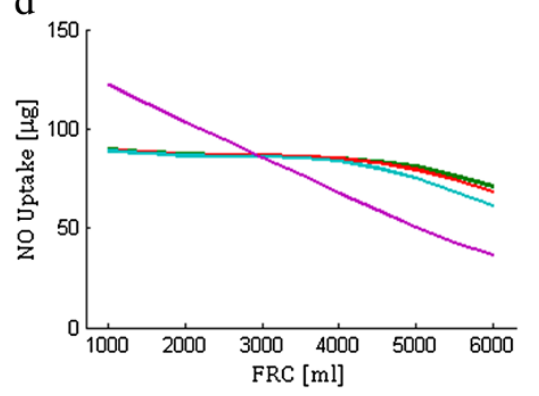

$\mathrm{f}$

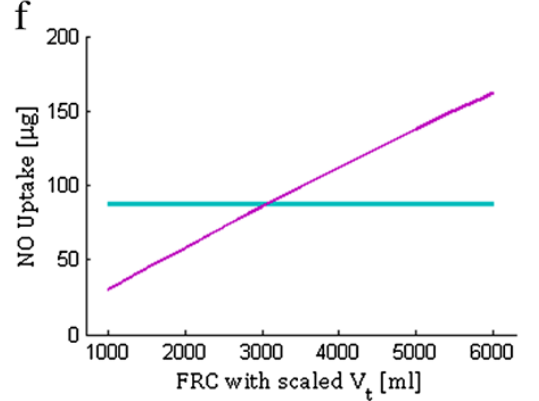

Figure 5 Total NO uptake over a 60 seconds time period for pulsed and constant concentration delivery. Plotted with varying (a) tidal volume, (b) inspiratory time fraction, (c) breathing frequency, (d) functional residual capacity (FRC), (e) expiratory time constant, and (f) varying FRC together with tidal volume, where tidal volume is scaled in proportion to FRC. When not the varied parameter, the following values were used: $F R C=3000 \mathrm{ml}, D_{\llcorner} N O=150 \mathrm{ml} / \mathrm{min} / \mathrm{mm} \mathrm{Hg}$, tidal volume $=500 \mathrm{ml}$, breath frequency $=12 \mathrm{~min}^{-1}$, inspiratory time fraction $=1 / 3$, and expiratory time constant $=0.6 \mathrm{~s}$.

dead space volume, and the diffusing capacity of the lung for $\mathrm{NO}\left(\mathrm{D}_{\mathrm{L}} \mathrm{NO}\right)$. In general, uptake efficiency was consistently higher for pulsed NO delivery than for constant concentration delivery. As will be discussed below, pulse time and delay influenced uptake efficiency more significantly as breath frequency increased, and as tidal volume decreased. In these circumstances, gas mixing in the conducting airways played an important role in determining uptake efficiency for pulsed delivery.

\section{Model verification}

In order to verify calculations made using the model presented above, predictions of alveolar and exhaled $\mathrm{NO}$ concentrations, and NO uptake efficiency, were compared with those made previously by Heinonen et al. [11]. Those authors constructed a model simulating bulk convection through a single channel, representing the conducting airways, supplying an elastic compartment, representing the alveolar region, and found good agreement with peak and end-tidal exhaled NO concentration measured during pulsed and constant concentration NO delivery to intubated, mechanically ventilated pigs. As seen in Table 2, predictions made using the present model were in close agreement with those made by Heinonen et al. [11]. The agreement between these two distinct models, and their consistency with in vivo data from an animal model, provides a measure of confidence in moving forward to make predictions regarding NO delivery to humans.

\section{Constant concentration versus pulsed dosing}

One practical application of the model presented here is to guide the design of pulsed NO dosing systems. A logical starting point is to tune pulse volume and timing 

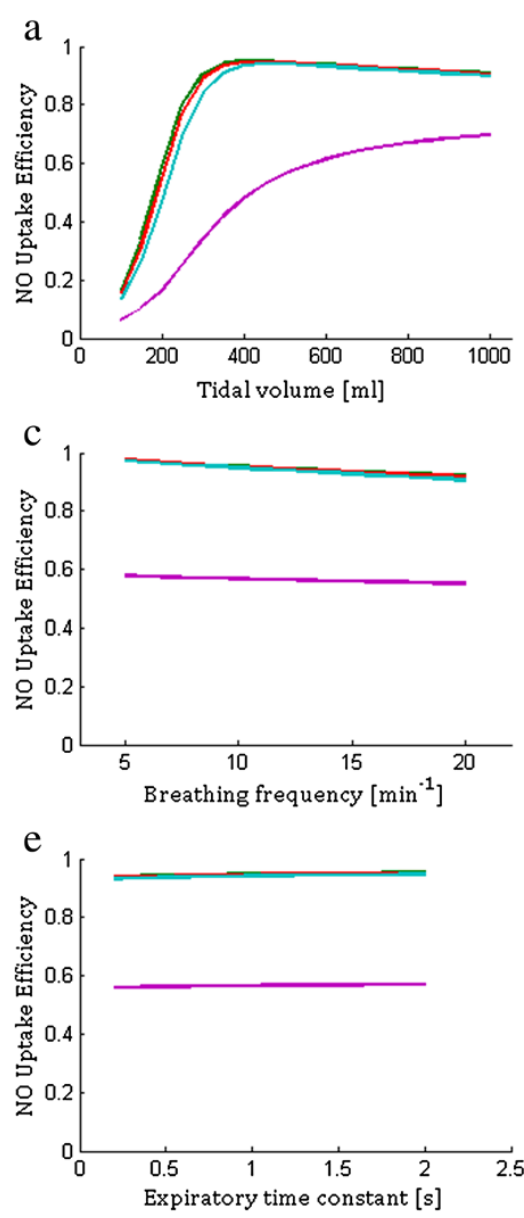

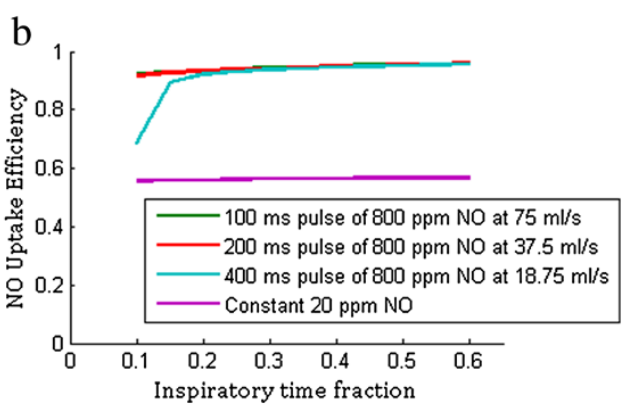

d
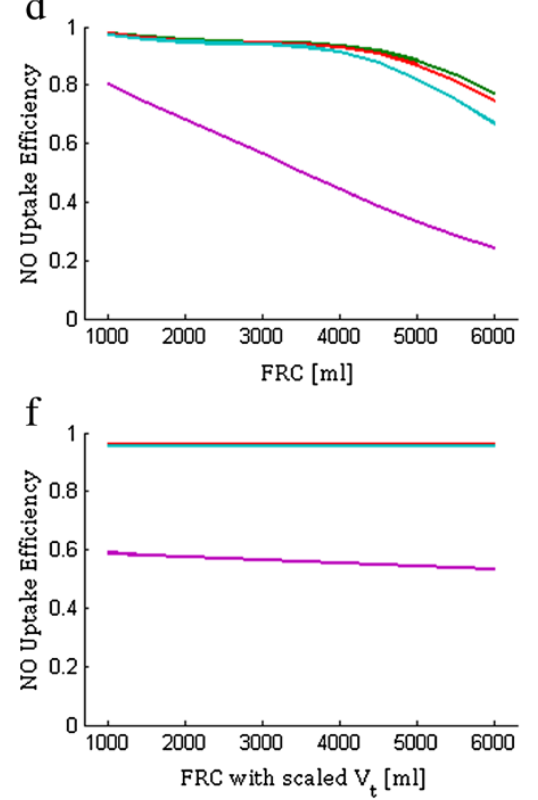

Figure 6 NO uptake efficiency for pulsed and constant concentration delivery. Plotted with varying (a) tidal volume, (b) inspiratory time fraction, (c) breathing frequency, (d) functional residual capacity (FRC), (e) expiratory time constant, and (f) varying FRC together with tidal volume, where tidal volume is scaled in proportion to FRC. When not the varied parameter, the following values were used: FRC $=3000 \mathrm{ml}$, $D_{\llcorner} N O=150 \mathrm{ml} / \mathrm{min} / \mathrm{mm} \mathrm{Hg}$, tidal volume $=500 \mathrm{ml}$, breath frequency $=12 \mathrm{~min}^{-1}$, inspiratory time fraction $=1 / 3$, and expiratory time constant $=0.6 \mathrm{~s}$.

so as to produce equivalent alveolar concentration and uptake as predicted for delivery of a given constant NO concentration, where dose-response relationships are more established. This was the approach adopted in selecting the $8 \mu \mathrm{g} \mathrm{NO} /$ breath pulses studied herein. As shown in Figure 4, for the base set of input parameters, variation in alveolar concentration over time is very similar for the three pulsed delivery modes as for constant delivery of $20 \mathrm{ppm}$ inhaled NO. NO uptake was also nearly identical between the pulsed and constant modes. Each input parameter was then varied independently to assess its influence on NO uptake, and results are presented in Figure 5. The same calculations are presented in terms of uptake efficiency in Figure 6. With the exception of respiratory rate, variation of NO uptake is predicted to be less influenced by input parameter variation for pulsed than for constant dosing. In particular, NO uptake for pulsed delivery is predicted to be relatively insensitive to tidal volume and FRC, except when tidal volume becomes small or FRC large, in which cases uptake is seen to decrease. Noting that conducting airway volume scaled with FRC, the latter effect arises due to incomplete transport of $\mathrm{NO}$ through the conducting airways during inhalation, such that an increasing fraction of $\mathrm{NO}$ is exhaled. When tidal volume was allowed to increase in proportion with FRC, as in Figures $5 f$ and $6 f$, NO uptake and uptake efficiency remained constant for pulsed dosing as FRC varied.

Of note, uptake efficiency was predicted to remain significantly greater for pulsed dosing than for constant dosing in all cases presented in Figure 6. This is seen as an advantage of pulsed delivery systems, in that less NO may be required to maintain an equivalent therapeutic effect. A potential further advantage of pulsed dosing systems is to improve correlation between NO dose and patient response. Under the assumption that therapeutic 
Table 3 Effects of pulse time and pulse delay on nitric oxide uptake efficiency for varied breathing patterns

\begin{tabular}{|c|c|c|c|c|c|}
\hline \multirow[b]{2}{*}{$\begin{array}{l}\text { Pulse } \\
\text { Time [ms] }\end{array}$} & \multirow[b]{2}{*}{$\begin{array}{c}\text { Pulse } \\
\text { Delay [ms] }\end{array}$} & \multicolumn{4}{|c|}{ Uptake efficiency } \\
\hline & & $\begin{array}{l}V t=500 \mathrm{ml} \\
f=12 \mathrm{~min}^{-1}\end{array}$ & $\begin{array}{l}V t=500 \mathrm{ml} \\
f=25 \mathrm{~min}^{-1}\end{array}$ & $\begin{array}{l}\mathrm{Vt}=250 \mathrm{ml} \\
\mathrm{f}=12 \mathrm{~min}^{-1}\end{array}$ & $\begin{array}{l}V t=250 \mathrm{ml} \\
\mathrm{f}=25 \mathrm{~min}^{-1}\end{array}$ \\
\hline \multirow[t]{4}{*}{100} & 0 & 0.94 & 0.89 & 0.88 & 0.81 \\
\hline & 50 & 0.94 & 0.89 & 0.85 & 0.72 \\
\hline & 100 & 0.94 & 0.89 & 0.81 & 0.59 \\
\hline & 200 & 0.94 & 0.88 & 0.70 & 0.24 \\
\hline \multirow[t]{4}{*}{200} & 0 & 0.94 & 0.89 & 0.84 & 0.70 \\
\hline & 50 & 0.94 & 0.89 & 0.80 & 0.57 \\
\hline & 100 & 0.94 & 0.88 & 0.76 & 0.42 \\
\hline & 200 & 0.94 & 0.86 & 0.63 & 0.14 \\
\hline \multirow[t]{4}{*}{400} & 0 & 0.94 & 0.88 & 0.74 & 0.42 \\
\hline & 50 & 0.94 & 0.86 & 0.68 & 0.31 \\
\hline & 100 & 0.94 & 0.81 & 0.61 & 0.22 \\
\hline & 200 & 0.93 & 0.62 & 0.46 & 0.07 \\
\hline
\end{tabular}

effects are closely related to uptake, uptake efficiency would ideally remain near 1.0 , or at least remain constant, such that the rate of NO uptake could be closely estimated based on the rate of NO delivery. This would allow dosing to be performed through monitoring the absolute amount (mass, volume, moles) of NO delivered, with the potential to improve dose-response correlations $[10,11]$.

\section{Effects of pulse delay}

While uptake efficiency remained near 1.0 for the majority of the parameter range presented in Figure 6 , the case of low tidal volume was further examined, as reported in Table 3. Here, the delay time between onset of inhalation and pulse delivery was also considered. At a resting breathing pattern with tidal volume of $500 \mathrm{ml}$ and breathing frequency of $12 \mathrm{~min}^{-1}$, uptake efficiency remained above 0.9 even for the extreme case of a $400 \mathrm{~ms}$ pulse, with $200 \mathrm{~ms}$ delay. In contrast, for rapid, shallow breathing with tidal volume of $250 \mathrm{ml}$ and breathing frequency of $25 \mathrm{~min}^{-1}$, uptake efficiency was lower, and much more sensitive to both pulse time and delay. In order to minimize these effects, a pulse time of $100 \mathrm{~ms}$ or less, with delay less than $50 \mathrm{~ms}$, is desirable. Making a comparison with pulsed oxygen delivery devices, as have previously been adapted for ambulatory NO delivery through nasal cannulae [12,13], a $50 \mathrm{~ms}$ delay is within the range of values reported for commercially available devices [23]. In turn, a pulse time of $100 \mathrm{~ms}$ is near reported values for the lowest pulse setting on the majority of devices [23]. Given that required pulse volumes for high concentration NO source gas will generally be smaller than for oxygen, pulse times at or below $100 \mathrm{~ms}$ are technically feasible.

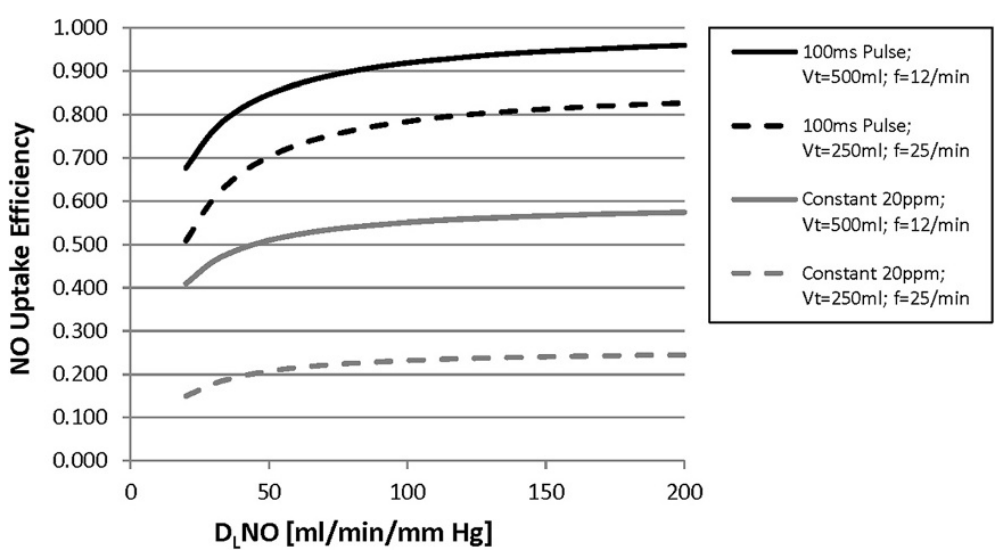

Figure 7 NO uptake efficiency is plotted against $D_{L}$ NO for pulsed and constant concentration delivery for two breathing patterns. FRC was held constant at $3000 \mathrm{ml}$, as was inspiratory time fraction at 1/3. 


\section{Uptake efficiency versus $D_{L} N O$}

All results discussed above were obtained from calculations in which the $\mathrm{D}_{\mathrm{L}} \mathrm{NO}$ was fixed at $150 \mathrm{ml} / \mathrm{min} / \mathrm{mm}$ $\mathrm{Hg}$. This falls approximately in the middle of the range reported by Zavorsky et al. [24] for healthy adults performing single-breath-hold maneuvers at rest. Significant variation between subjects is expected even in healthy populations, and certainly in patients with respiratory or cardiovascular disease. For example, in patients with pulmonary arterial hypertension $(\mathrm{PAH})$, average $\mathrm{D}_{\mathrm{L}} \mathrm{NO}$ values have been reported as approximately $60-80 \mathrm{ml} / \mathrm{min} / \mathrm{mm}$ $\mathrm{Hg}$ [25,26], with values below $50 \mathrm{ml} / \mathrm{min} / \mathrm{mm} \mathrm{Hg}$ reported in individual patients [25]. Figure 7 demonstrates considerable sensitivity of uptake efficiency to $\mathrm{D}_{\mathrm{L}} \mathrm{NO}$ within lower ranges, especially for pulsed delivery. In contrast, at higher ranges, uptake efficiency was much less sensitive to $D_{L} N O$, indicative of excess capacity to take up NO at typical therapeutic dose levels in lungs which maintain normal, or nearnormal, alveolar membrane conductance. It is interesting to comment that even for the most efficient case studied, $100 \mathrm{~ms}$ pulse with zero delay, uptake efficiency is predicted to lie between approximately 0.7 and 0.9 for $\mathrm{D}_{\mathrm{L}} \mathrm{NO}$ values typical of PAH patients. This presents an apparent discrepancy with clinical experience delivering pulsed $\mathrm{NO}$ to $\mathrm{PAH}$ patients, where no detectable exhaled NO has been reported $[13,15]$, suggesting an uptake efficiency near 1.0. It may be that exhaled NO concentrations in clinical evaluations were simply below the detection limit of the analyzers employed (peak exhaled NO would likely not exceed 1 or $2 \mathrm{ppm}$, and last fractions of a second, while end-tidal values would lie well below 1 ppm).

Based on present understanding, it appears that the amount of NO delivered is not directly predictive of the amount of NO uptake, such that monitoring NO delivery alone cannot be considered a substitute for monitoring uptake. As variation in uptake efficiency is more pronounced at low $\mathrm{D}_{\mathrm{L}} \mathrm{NO}$, considerable dose titration may be required for patients with initially low $D_{L} N O$ that receive NO therapy. This is true for both pulsed dosing and constant concentration dosing. In relative terms, pulsed dosing offered considerable improvement in uptake efficiency compared with constant concentration dosing even for the lowest $\mathrm{D}_{\mathrm{L}} \mathrm{NO}$ values studied.

\section{Nitrogen dioxide production}

It may be noted that reaction between $\mathrm{NO}$ and oxygen to produce nitrogen dioxide $\left(\mathrm{NO}_{2}\right)$ has not been included in the present model description. In fact, a version of the model was built to include such effects, but $\mathrm{NO}_{2}$ production was extremely small. This can be deduced from back of the envelope calculations, given that the chemical kinetics and rate of reaction between $\mathrm{NO}$ and oxygen are well known [27]. For example, at a representative inhalation flow rate of $300 \mathrm{ml} / \mathrm{s}$, the residence time of gases passing through the conducting airways is less than $1 \mathrm{~s}$. For 20 ppm NO reacting with $100 \%$ oxygen, less than 10 parts per billion (ppb) $\mathrm{NO}_{2}$ are produced per second. While initial NO concentrations are higher for pulsed delivery, dispersion is rapid (Figure 3b) such that these higher concentrations are very short lived. In the alveolar region, NO concentrations are much lower: assuming an alveolar NO concentration maintained at $1 \mathrm{ppm}$ through supply from the conducting airways, the time to produce $1 \mathrm{ppm} \mathrm{NO}_{2}$, even in $100 \%$ oxygen, is more than 10 hours - and this assumes $\mathrm{NO}_{2}$ accumulates in the alveolar region with no uptake. While such conditions may be possible during extended NO delivery to patients with poorly ventilated and poorly perfused lung regions, the risk of $\mathrm{NO}_{2}$ production in the lungs is small in comparison with the risk of $\mathrm{NO}_{2}$ developing in breathing circuits used to convey

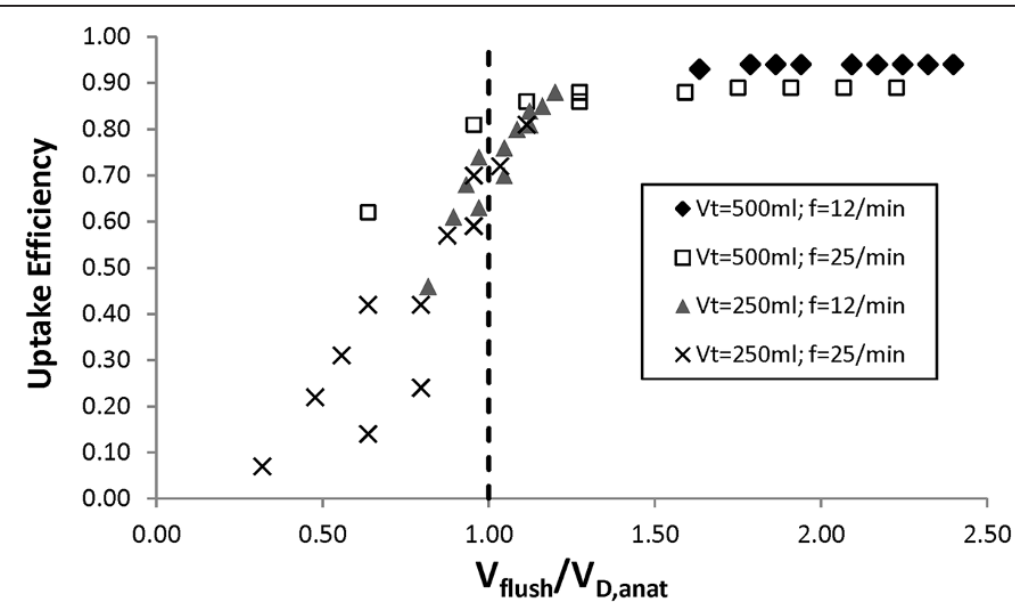

Figure 8 Uptake efficiency for pulsed delivery from Table 3 is plotted against the ratio between flush volume $\left(V_{f}\right)$ and anatomical dead space volume $\left(\mathbf{V}_{\mathrm{D}, \text { anat }}\right)$. The flush volume is defined as the tidal volume minus the total volume inhaled during the delay time and pulse time. 
gases to the patient. In the latter case, the combination of sufficiently large $\mathrm{NO}$ concentrations and residence times to produce appreciable amounts of $\mathrm{NO}_{2}$ may exist, and precautions to avoid excess $\mathrm{NO}_{2}$ production have been documented [10,28].

\section{Conducting airways model}

The present model treated the conducting airways as a series of individual generations, and included axial dispersion of NO through the empirical coefficient proposed by Scherer et al. [21]. One may reasonably question whether modelling axial dispersion provides any significant insight in comparison with simpler models. In describing pulsed oxygen delivery, other investigators have used idealized bulk analysis based on relative volumes of the conducting airways (anatomical dead space) and tidal breath $[29,30]$. With regards to the present work, Figure 8 highlights the significance of including mixing in the conducting airways as opposed to a bulk analysis based on relative airway and tidal volumes. The 'flush volume', $V_{f}$, is defined as the tidal volume minus the total volume inhaled during the delay time and pulse time. Under a volumes-based analysis, so long as the flush volume is greater than the volume of the anatomical dead space, all NO delivered in the pulse is swept into the alveolar region, and made available for uptake. In contrast, Figure 8 displays uptake efficiency as low as 0.7 in the region of the plot where flush volume exceeds dead space volume, indicating that a portion of NO remains in the conducting airways at the end of inhalation (this was confirmed by viewing generational concentration data). Accordingly, gas mixing in the conducting airways plays an important role in determining the efficiency of pulsed delivery systems.

\section{Limitations}

Several limitations of the present model present opportunities for future work. First, extension to multiple paths and multiple compartments would allow the interplay between regional variation of respiratory mechanics, ventilation, perfusion, and uptake efficiency to be explored. Second, the possibility of significant concentration gradients within the alveolar air spaces could be explored by moving to a multigeneration model of the alveolar region [31,32], with potential impact on total uptake efficiency. Finally, the present model treated the extrathoracic airway as a single tube, representative of an endotracheal tube, while pulsed delivery has frequently been linked with long term administration of NO through nasal cannulae. Depending on the cannula design, mixing of $\mathrm{NO}$ source gas with room air, and with any additional supplemental oxygen, will occur during transit through the nasal air passages and will determine boundary conditions entering the trachea. More accurate representation of concentration profiles exiting the extrathoracic airway will likely require bench experiments, or computational fluid dynamics simulations, specific to a given patient interface and nasal airway geometry.

\section{Conclusions}

In conclusion, pulsed NO delivery offers significant improvement in uptake efficiency compared with constant concentration delivery. However, uptake from the alveolar region can depend on pulse timing, tidal volume, respiratory rate, lung and dead space volume, and $\mathrm{D}_{\mathrm{L}} \mathrm{NO}$. It is predicted that variation in uptake efficiency with breathing pattern can be moderated using a pulse time of less than $100 \mathrm{~ms}$, with a delay of less than $50 \mathrm{~ms}$ between the onset of inhalation and pulse delivery. Nonlinear variation in uptake efficiency with $\mathrm{D}_{\mathrm{L}} \mathrm{NO}$ was predicted, with uptake efficiency falling off sharply as $\mathrm{D}_{\mathrm{L}} \mathrm{NO}$ decreased below $\sim 50-60 \mathrm{ml} / \mathrm{min} / \mathrm{mm} \mathrm{Hg}$. Gas mixing in the conducting airways played an important role in determining uptake efficiency for pulsed delivery.

\section{Competing interests}

At the time of the study, all authors were employed by Air Liquide. Air Liquide markets medical nitric oxide in several geographic regions.

\section{Authors' contributions}

AM conceived of the study, participated in developing the model, and wrote the manuscript. CJ participated in developing the model, wrote code to conduct the model calculations, and contributed to drafting the manuscript. IK participated in the conception and design of the study, and edited the manuscript. GC participated in the conception and design of the study. All authors read and approved the final manuscript

\section{Author details}

'Delaware Research and Technology Center, American Air Liquide, Newark, DE, USA. ${ }^{2}$ Medical Gases Group, Air Liquide Santé International, 1 chemin de la Porte des Loges, Les Loges-en-Josas 78354, France. ${ }^{3}$ Department of Mechanical Engineering, Lafayette College, Easton, PA, USA. ${ }^{4}$ Current address: Department of Mechanical Engineering, University of Alberta, Edmonton, AB, Canada. ${ }^{5}$ Current address: 99 Fieldsend, Beaconsfield, QC H9W 5J2, Canada.

Received: 26 November 2013 Accepted: 16 January 2014

Published: 22 January 2014

\section{References}

1. Frostell C, Fratacci M, Wain J, Jones R, Zapol W: Inahled nitric oxide. A selective pulmonary vasodilator reversing hypoxic pulmonary vasoconstriction. Circulation 1991, 83:2038-2047.

2. Roberts J, Polaner D, Zapol W, Lang P: Inhaled nitric oxide in persistent pulmonary hypertension of the newborn. Lancet 1992, 340(8823):818-819.

3. Committee on Fetus and Newborn: Use of inhaled nitric oxide. Pediatrics 2000, 106:344-345

4. Griffiths M, Evans T: Inhaled nitric oxide therapy in adults. N Engl J Med 2005, 353:2683-2695.

5. Checchia P, Bronicki R, Goldstein B: Review of inhaled nitric oxide in the pediatric cardiac surgery setting. Pediatr Cardiol 2012, 33(4):493-505.

6. OZ M, Ardehali A: Collective review: perioperative uses of inhaled nitric oxide in adults. Heart Surg Forum 2004, 7(6):E584-E589.

7. Young J, Roberts M, Gale L: Laboratory evaluation of the I-NOvent nitric oxide delivery device. Br J Anaesth 1997, 79:398-401.

8. Kirmse M, Hess D, Fujino Y, Kacmarek R, Hurford W: Delivery of inhaled nitric oxide using the ohmeda INOvent delivery system. Chest 1998, 113:1650-1657.

9. Tworetzky W, Bristow J, Moore P, Brook M, Segal M, Brasch R, Hawgood S, Fineman J: Inhaled nitric oxide in neonates with persistent pulmonary hypertension. Lancet 2001, 357(9250):118-120. 
10. Imanaka H, Hess D, Kirmse M, Bigatello L, Kacmarek R, Steudel W, Hurford W: Inaccuracies of nitric oxide delivery systems during adult mechanical ventilation. Anesthesiology 1997, 86:676-688.

11. Heinonen E, Hogman M, Merilainen P: Theoretical and experimental comparison of constant inspired concentration and pulsed delivery in NO therapy. Intensive Care Med 2000, 26:1116-1123.

12. Ivy D, Griebel J, Kinsella J, Abman S: Acute hemodynamic effects of pulsed delivery of low flow nasal nitric oxide in children with pulmonary hypertension. J Pediatr 1998, 133:453-456.

13. Channick R, Newhart J, Johnson F, Williams P, Auger W, Fedullo P, Moser K: Pulsed delivery of inhaled nitric oxide to patients with primary pulmonary hypertension. Chest 1996, 109:1545-1549.

14. Katayama Y, Higenbottam T, Akamine CGS, Demoncheaux E, Smith A, Siddons T: Minimizing the inhaled dose of NO with breath-by-breath delivery of spikes of concentrated gas. Circulation 1998, 98:2429-2432.

15. Barst R, Channick R, Ivy D, Goldstein B: Clinical perspectives with longterm pulsed inhaled nitric oxide for the treatment of pulmonary arterial hypertension. Pulmonary Circulation 2012, 2(2):139-147.

16. Finlay W, Lange C, King M, Speert D: Lung delivery of aerosolized dextran. Am J Respir Crit Care Med 2000, 161:97-107.

17. Phillips C, Kaye S, Schroter R: A diameter-based reconstruction of the branching pattern of the human bronchial tree. Respir Physiol 1994, 98:193-217.

18. Finlay W: The Mechanics of Inhaled Pharmaceutical Aerosols. London: Academic Press; 2001.

19. Ben Jebria A: Convective gas mixing in the airways of the human lung comparison of laminar and turbulent dispersion. Trans Biomed Eng 1984, BME-31(7):498-506.

20. Taylor G: Dispersion of soluble matter in solvent flowing slowly through a tube. Proc R Soc 1953, 219A:186-203.

21. Scherer P, Shendalman L, Greene N, Bouhuys A: Measurement of axial diffusivities in a model of the bronchial airways. J App/ Physiol 1975, 38:719-723.

22. Darquenne C, Paiva M: One-dimensional simulation of aerosol transport and deposition in the human lung. J App/ Physio/ 1994, 77(6):2889-2898.

23. Chatburn R, Williams T: Performance comparison of 4 portable oxygen concentrators. Respir Care 2010, 55(4):433-442.

24. Zavorsky G, Cao J, Murias J: Reference values of pulmonary diffusing capacity for nitric oxide in an adult population. Nitric Oxide 2008, 18:70-79.

25. van der Lee I, Zanen P, Grutters J, Snijder R, van der Bosch J: Diffusing capacity for nitric oxide and carbon monoxide in patients with diffuse parenchymal lung disease and pulmonary arterial hypertension. Chest 2006, 129:378-383.

26. Farha S, Laskowski D, George D, Park M, Tang W, Dweik R, Erzurum S: Loss of alveolar membrand diffusing capacity and pulmonary capillary blood volume in pulmonary arterial hypertension. Respir Res 2013, 14:6.

27. Tsukahara H, Ishida T, Mayumi M: Gas-phase oxidation of nitric oxide: chemical kinetics and rate constant. Nitric Oxide Biol Chem 1999, 3(3):191-198.

28. Lovich M, Bruno N, Plant C, Wei A, Vasquez G, Johnson B, Fine D, Gilbert R: Use of ultra pure nitric oxide generated by the reduction of nitrogen dioxide to reverse pulmonary hypertension in hypoxemic swine. Nitric Oxide 2011, 24:204-212.

29. Tiep B, Christopher K, Spofford B, Goodman J, Worley P, Macy S: Pulsed nasal and transtracheal oxygen delivery. Chest 1990, 97(2):364-368.

30. McCoy R: Oxygen-conserving techniques and devices. Respir Care 2000, 45(1):95-104.

31. Tawhai $M$, Hunter $P$ : Characteristic respiratory airway gas mixing using a lumped parameter model of the pulmonary acinus. Respir Physiol 2001, 127:241-248.

32. Foucquier A, Filoche M, Moreira A, Andrade J Jr, Arbia G, Sapoval B: A first principles calculation of the oxygen uptake in the human pulmonary acinus at maximal exercise. Respir Physiol Neurobiol 2013, 185:625-638.

doi:10.1186/2045-9912-4-1

Cite this article as: Martin et al:: Variability in uptake efficiency for pulsed versus constant concentration delivery of inhaled nitric oxide. Medical Gas Research 2014 4:1.

\section{Submit your next manuscript to BioMed Central and take full advantage of:}

- Convenient online submission

- Thorough peer review

- No space constraints or color figure charges

- Immediate publication on acceptance

- Inclusion in PubMed, CAS, Scopus and Google Scholar

- Research which is freely available for redistribution 